\title{
BREAST CONSERVING SURGERY AWARENESS AND ACCEPTANCE AMONG FEMALE NURSES IN IRRUA SPECIALIST TEACHING HOSPITAL
}

\author{
${ }^{1}$ Okomayin, A. A., ${ }^{* 2}$ Brotobor, D., ${ }^{1}$ Onyeanusi, A. E., \& ${ }^{3}$ Alili, I. B. \\ ${ }^{1}$ Department of Surgery, Irrua Specialist Teaching Hospital, Irrua, Edo State, Nigeria \\ ${ }^{* 2}$ Department of Nursing, Ambrose Ali University, Ekpoma, Edo State, Nigeria \\ ${ }^{3}$ Department of Nursing Services, Irrua Specialist Teaching Hospital, Irrua, Edo State, Nigeria
}

*Corresponding Author Email: deliverancebrotobor@gmail.com Phone: +2349055468987

\section{ABSTRACT}

Introduction: Breast Conserving Surgery (BCS) is oncologically safe for eligible patients with breast cancer and has enormous physical and psychological benefits. Despite this, the mastectomy rate in many centres is still very high. Nurses are frontline staff in healthcare settings and have great contact with the patients. The level of their awareness would have a great impact on patients eligible for breast conservation seeking expert opinion. This study explored the awareness, perception and acceptance of BCS among female nurses in a rural Nigeria tertiary hospital.

Methodology: A quasi-structured self-questionnaire was distributed to 235 nurses using a convenient sampling method. The responses on 219 adequately filled questionnaires were entered into an IBM SPSS Statistics Data Document (version 21.0) for analysis. Categorical variables were presented in counts and percentages. Association between the acceptance of BCS versus its awareness, equivalence to TM and years of nursing practice were tested using Chi-square probability test and a p-value of $<0.05$ was considered statistically significant.

Result: The 219 participants had a good representation of junior and senior nurses among whom $80.4 \%$ were at least 45 years old and $82.2 \%$ were married. The nurses were mostly general nursing practitioners $(76.7 \%)$ and $49.3 \%$ of the nurses had practised for a duration not less than 10 years of age. The $126(57.5 \%)$ nurses, who described BCS as the surgical removal of a cancerous breast lump short of mastectomy, were considered to be aware of BCS irrespective of their understanding of complementary treatment modalities, eligibilities, comparative advantages to TM and certainty of its oncologic safety. The lack of ready access to radiotherapy centres (54.3\%) and delay/overcrowding of these facilities (42.5\%) were recognised respectively as major local challenges to BCS practices. The equivalence of BCS to TM was affirmed in $44.3 \%$ of the nurses and $35.6 \%$ had participated in managing breast cancer patients using the conservative surgical approach. $57.1 \%$ were willing to accept BCS or recommend it for an eligible friend or relative and no statistically significant association was observed among those who accepted BCS when matched with the level of awareness or the duration of nursing practice. A higher and significant level of acceptance of BCS was noted among those aware of its oncologic equivalence to TM $(\mathrm{p}$-value $=0.000)$

Conclusion: This study demonstrated gaps in knowledge of BCS among nurses who are stakeholders in assisting patients make the right decision. This knowledge gap in the perception of BCS will interfere with the ability of the nurse to adequately counsel patients in need of their expert opinion. The awareness of the oncologic equivalence of BCS to TM increased its acceptance significantly. An increase in public awareness and education of nurses is required to improve the acceptance rate of BCS in our practice. Caregivers should also devise effective means of communication to encourage eligible patients for breast conservation

Keywords: Breast Cancer, Breast Conserving Surgery (BCS), Total Mastectomy (TM), Awareness, Perception

LICENSE: This work by Open Journals Nigeria is licensed and published under the Creative Commons Attribution License 4.0 International License, which permits unrestricted use, distribution, and reproduction in any medium, provided this article is duly cited.

COPYRIGHT: The Author(s) completely retain the copyright of this published article.

OPEN ACCESS: The Author(s) approves that this article remains permanently online in the open access (OA) model.

QA: This Article is published in line with "COPE (Committee on Publication Ethics) and PIE (Publication Integrity \& Ethics)". 


\section{INTRODUCTION}

Globally, cancer of the breast is the most common tumour and the commonest cause of cancer death among women (Coleman et al., 2008; Akram et al., 2017). It is a global health challenge with a rising incidence and up to 100,000 new cases are reported to occur every year in Nigeria (Jedy-Agba et al., 2012). The gold standard for treating localized and operable breast cancer worldwide is surgery - mastectomy or breast conserving surgery (BCS) (Biganzoli et al., 2012). Total mastectomy (TM) refers to the removal of the entire breast, while BCS preserves a portion of it that is uninvolved. BCS is best defined as any surgical intervention in the breast short of TM that removes the primary tumour with an envelope of an adequate margin of grossly normal-appearing surrounding breast tissues (Dorval et al., 1998). The other terms used to describe this operation are lumpectomy, wide local excision, quadrantectomy, segmental mastectomy (segmentectomy), partial mastectomy and tylectomy (Dorval et al., 1998). It is usually followed by the assessment of the regional lymph node status and/or dissection/clearance through a separate incision in the axilla, adjuvant radiotherapy to the breast, chemotherapy (adjuvant or neoadjuvant), hormonal therapy or immune therapy when indicated (Fisher, 1998; Fisher et al., 2002; Newton and Washington, 2003). BCS originated from an innate feminine desire to preserve the native breast and several meta-analyses that demonstrated its oncological equivalence to TM (no difference in overall survival and recurrence rates) in early-stage breast cancers (Arriagada et al., 1996; van Dongen et al., 2000; Fisher et al., 2002; Morrow et al., 2002; Mahmood et al., 2012). Breast conservation has a huge psychological impact on the woman's body image, nude appearance, sexuality and significantly improves her quality of life (QOL) (Coleman et al., 2008; Akram et al., 2017).

The indications for BCS have been updated severally, enhanced by tumour response to neoadjuvant chemotherapy and the improved cosmetic outcomes of oncoplastic surgeries (Bajaj et al., 2004; Chen et al., 2004; Mieog et al., 2007). The major indications now include the patient's choice and willingness (to undergo radiotherapy and postoperative surveillance protocol), oncological feasibility and absence of contraindications to radiation therapy. The contraindications are fewer and include the patient's refusal and a lack of motivation, unattainable free surgical margins (eg multifocal/multicentric tumours, extensive calcifications), increase likelihood of poor cosmesis after BCS (eg very large tumour compared to the size of the breast), known genetic susceptibility and when radiotherapy is contraindicated or not feasible (Morrow, 2005; Fajdic et al., 2013). In developing countries as Nigeria, local challenges such as ignorance, rural location, lack of oncoplastic surgical expertise and issues with radiotherapy (availability, affordability, facility crowding and delays) are also considered during the decision making for breast conservation. Though BCS is less invasive than mastectomy, it is not without complications. The complications include reoperation for positive margins, poor cosmetic outcomes, breast deformities (volumetric, retraction, contour), chronic pain syndromes, increased risk of in-breast recurrence and anxieties over possible recurrence and remnant cancer (Singletary, 2002). Some of the aforementioned benefits of BCS do not apply to a pendulous breast (Singletary, 2002).

Despite the enormous advantages of BCS, its increasing eligibility and the innate feminine desire for breast preservation, the mastectomy rate is relatively high in many countries (Dragun et al., 2012; Kummerow et al., 2015). Evidence from local experience shows an overwhelmingly high mastectomy rate, and many women opt for mastectomy for the wrong reasons and are thus deprived of the advantages of breast preservation. Some of the factors contributing to th e high mastectomy rates include misinformation, wrong beliefs, exaggerated fears and late 
presentation which in itself lead to a more advanced disease pattern at presentation (Mac Bride et al., 2013; Gu et al., 2017).

In Nigeria, the majority of women with breast cancer are relatively young (Adesunkanmi et al., 2006; Olasehinde et al., 2019) and mastectomy which is the most commonly performed surgical treatment in Nigeria for breast cancer, will cause greater psychological concerns for these women (Adebamowo and Adekunle, 1999; Ogundiran et al., 2013). Olasehinde et al. (2013) explored the experiences of young Nigerian women after mastectomy in a study and observed that many of the women who had mastectomy wished they had BCS or breast reconstruction after mastectomy. In another study in Singapore, nearly one-fifth of women regretted their decision to undergo mastectomy and felt that they would choose BCT if they had the opportunity to choose again (Lee et al., 2018). These desires reflect the innate feminine satisfaction of having a breast or its semblance. For eligible females, the decision for BCS versus mastectomy involves several determinants such as age, personal beliefs, personal preference, education, comfort level, situational awareness, quality and appropriateness of available care, geographical location, ethnicity, religion as well as the influence of the managing team. Wrong perceptions often lead to wrong decision making. Some patients believe that TM is safer because it involves more extensive surgery. These patients presume BCS will result in a lower recurrence or enable them to avoid chemotherapy (Teh et al., 2014; Gu et al., 2017). In Nigeria, the non-acceptance of TM is a major cause of late presentation, delayed surgical treatment, defaults from follow up care and discharges against medical advice (Ajekigbe et al., 1991; Elenwo and Ijah, 2020).

Nurses as frontline staff in the healthcare settings have great contact with the patients. They use the best available evidence in their judgements to influence key decisions within the healthcare team (Thomson et al., 2004). Their level of awareness and perception of BCS would have a great impact on the patients who often ask them lots of questions. Therefore, this study aims to explore BCS awareness and perception among them.

\section{MATERIALS AND METHODS}

This was a questionnaire-based exploratory survey of female nurses in Irrua Specialist Teaching Hospital (ISTH) carried out in 2021 between April and August, following ethical approval by ISTH-Health Research and Ethics Committee (Protocol Number: ISTH/HREC /20210103/159).

\section{STUDY DESIGN}

Prospective exploratory study

\section{STUDY LOCATION}

ISTH is a major referral centre in Edo state and neighbouring states. It is located along the Benin-Abuja expressway in Irrua, the headquarters of Esan Central LGA in Edo Central Senatorial District, serving the Central, Northern and parts of the Southern District of the State.

\section{STUDY DURATION}

April and August 2021.

\section{SAMPLE SIZE}

214 female nurses. 


\section{SAMPLE SIZE CALCULATION}

The sample size (n) for this study was calculated using Taro Yamane's method formula; $n=N /\{1+N(e) 2\}$, where: 'N' represents the population of female nurses in ISTH (which is 462), and 'e' signifies error margin of 0.05 at $95 \%$ confidence interval. With $10 \%$ attrition added to compensate for missing and inappropriately filled questionnaires, the sample size was adjusted from 214 to 235 .

\section{SUBJECT ELIGIBILITY}

All the female nurses were considered eligible for participation unless they decline consent.

\section{INCLUSION}

Nurses in the various departments of the hospital who are females.

\section{EXCLUSION}

Those who declined participation in the study.

\section{PROCEDURE AND METHODOLOGY}

We designed a quasi-structured self-questionnaire and performed face validity on it. The questionnaire had three (3) sections containing closed and open-ended questions. Section 1 contained information on the socio-demographic data of the nurses, current cadre and posting, area of specialization and the duration of practice. Section 2 explored the awareness and knowledge of the nurses on BCS, terminologies used to describe BCS, complementary treatment modalities, eligibilities, perceived advantages and disadvantages in comparison to TM, the nurse's participation in any patient managed with BCS and the attendant local challenges. Section 3 assessed the acceptance of BCS by the nurses as a treatment option for breast cancer and the factors that might influence an individual's choice of BCS viza-viz mastectomy. 235 questionnaires were distributed to the nurses using convenient sampling to cover the 3 duty shifts for 2 months. Seven (7) of the 226 questionnaires retrieved were excluded from the analysis as they were either blank or inadequately filled.

\section{DATA COLLATION AND ANALYSIS}

Data from 219 questionnaires were inputted into an IBM SPSS Statistics Data Document (version 21) and analysed. The categorical data were presented in counts and percentages. Association between the acceptance of BCS versus its awareness, equivalence to TM and years of nursing practice were tested using Chi-square probability test and a pvalue of $<0.05$ was considered statistically significant.

\section{RESULTS}

\section{DEMOGRAPHICS OF PARTICIPANTS}

The demographic analysis of the participant nurses (table 1 and figure 1) shows that the majority of them were at least 45 years $(80.4 \%)$, married (82.2\%), Christians (92.7\%), of Esan origin (55.3\%), and there was a good representation of junior and senior nurses (NO 2 to $\mathrm{CNO}$ ). Most participants were specialised in general nursing and there were only a handful of nurses in the other specialities. $49.3 \%$ of the nurses had practised for at least 10 years and $78.5 \%$ were spread across the departments of medicine, surgery, paediatric and O\&G (table 2). 
Table 1: Socio-demographic Characteristics of the Participants

\begin{tabular}{llll}
\hline Characteristics & $\begin{array}{l}\text { Number } \\
(\mathbf{n = 2 1 9})\end{array}$ & $\begin{array}{l}\text { Percentage } \\
(\boldsymbol{\%})\end{array}$ & $\begin{array}{l}\text { Cumulative } \\
\text { Percentage } \\
(\boldsymbol{\%})\end{array}$ \\
\hline Age Group & & & \\
$21-25$ & 14 & 6.4 & 6.4 \\
$26-30$ & 25 & 11.4 & 17.8 \\
$31-35$ & 61 & 27.9 & 45.7 \\
$36-40$ & 46 & 21.0 & 66.7 \\
41-45 & 30 & 13.7 & 80.4 \\
46 above & 43 & 19.6 & 100.0 \\
Marital Status & & & \\
Single & 37 & 169 & 16.9 \\
Married & 180 & 82.2 & 99.1 \\
Widowed/Divorced & 2 & 0.9 & 100.0 \\
Religion & & & \\
Christianity & 203 & 92.7 & 92.7 \\
Islam & 15 & 6.8 & 99.5 \\
Others & 1 & 0.5 & 100.0 \\
Tribe & & & \\
Esan & 121 & 55.3 & 55.3 \\
Bini & 19 & 8.7 & 64.0 \\
Afemai & 21 & 9.6 & 73.6 \\
Ibo & 27 & 12.3 & 85.9 \\
Yoruba & 13 & 5.9 & 91.8 \\
Others & 13 & 5.9 & 97.7 \\
Unspecified & 5 & 2.3 & 100.0 \\
\hline
\end{tabular}

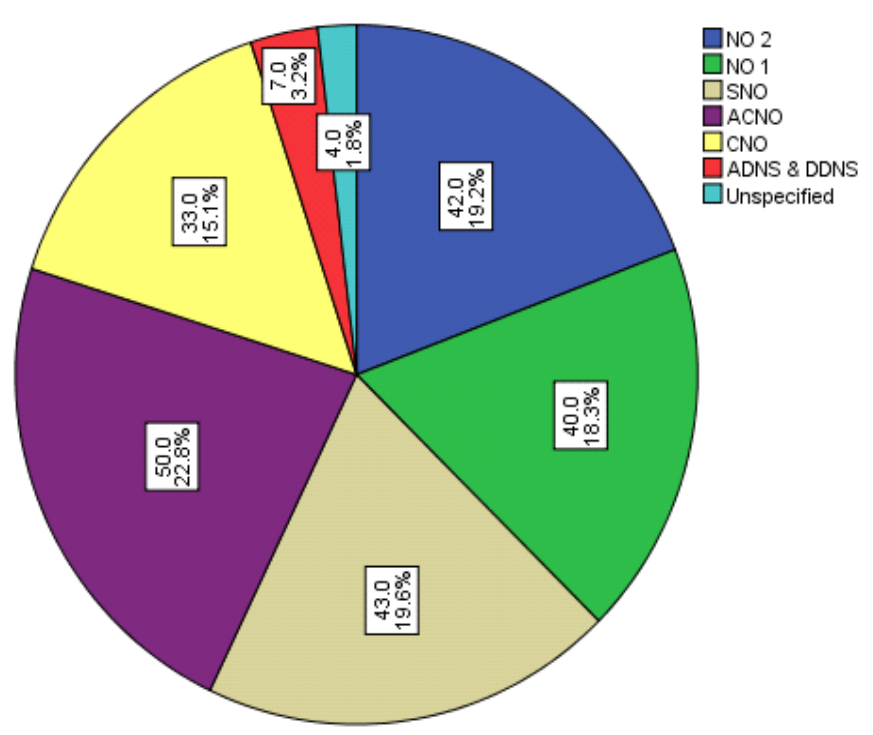

Figure 1: Cadre of Participant Nurses 
Table 2: Specialization, Years of Practice and Current Posting

\begin{tabular}{|c|c|c|c|}
\hline Characteristics & $\begin{array}{l}\text { Number } \\
(n=219)\end{array}$ & $\begin{array}{l}\text { Percentage } \\
(\%)\end{array}$ & $\begin{array}{l}\text { Cumulative } \\
\text { Percentage }(\%)\end{array}$ \\
\hline \multicolumn{4}{|l|}{ Area of Specialization } \\
\hline General & 168 & 76.7 & 76.7 \\
\hline Nursing & 13 & 5.9 & 82.6 \\
\hline Paediatric & 10 & 4.6 & 87.2 \\
\hline Peri-Op. & 9 & 4.1 & 91.3 \\
\hline Nursing & 15 & 6.8 & 98.1 \\
\hline $\mathrm{O} \& \mathrm{G}$ & 4 & 1.8 & 100.0 \\
\hline \multicolumn{4}{|l|}{ Others } \\
\hline \multicolumn{4}{|l|}{ Unspecified } \\
\hline \multicolumn{4}{|l|}{ Years of Practice } \\
\hline $1-3$ & 32 & 14.6 & 14.6 \\
\hline $4-6$ & 44 & 20.1 & 34.7 \\
\hline $7-9$ & 35 & 16.0 & 50.7 \\
\hline 10 above & 108 & 49.3 & 100.0 \\
\hline \multicolumn{4}{|l|}{ Current Posting } \\
\hline Medicine & 54 & 24.7 & 24.7 \\
\hline Surgery & 51 & 23.3 & 47.9 \\
\hline Paediatric & 36 & 16.4 & 64.3 \\
\hline $\mathrm{O} \& \mathrm{G}$ & 31 & 14.2 & 78.5 \\
\hline Theatre & 10 & 4.6 & 83.1 \\
\hline Others & 35 & 16.0 & 99.1 \\
\hline Unspecified & 2 & 0.9 & 100.0 \\
\hline
\end{tabular}

\section{PERCEPTION (AWARENESS AND KNOWLEDGE) OF BCS VERSUS MASTECTOMY}

Table 3 x-rayed the perception of the nurses on BCS viz-a-viz total mastectomy (TM). More than two-thirds of the participants were familiar with the terminology 'BCS' and aware of its use as a surgical treatment option for the management of breast cancer. 126 (57.5\%) nurses described BCS as the surgical removal of a cancerous breast lump short of mastectomy. This category was considered to be aware of BCS irrespective of their understanding of the complementary treatment modalities, eligibilities, advantages and oncologic safety. BCS was also called lumpectomy, partial mastectomy, WLE, excision biopsy, quadrantectomy and segmental mastectomy in $42 \%, 34.2 \%, 26 \%, 21 \%$, $20.1 \%$ and $17.8 \%$ of participants respectively. Chemotherapy $(55.7 \%)$ and radiotherapy $(48.9 \%)$ were recognised by most of the participants as additional treatment modalities after a BCS; followed by axillary surgery/dissection (16.4\%), hormonal therapy (10\%) and immune therapy (3.2\%).

On the superiority of BCS compared to TM, 62.1\% believe it will improve psychological well-being and QOL of the patient, 33.3\% believed it will preserve the woman's nude appearance or beauty and $26.9 \%$ believed it preserves the native breast. On the contrary, $70.3 \%$ believed TM will lower the local recurrence rate compared to BCS and $12.8 \%$ erroneously agreed there is no need for further treatment after a TM. Early-stage and small size breast cancers were considered by many $(71.2 \%$ and $54.8 \%)$ as eligibility criteria for BCS. $55.3 \%, 52.5 \%$ and $8.2 \%$ respectively attributed their fears for BCS to fear of recurrence, undue anxieties over recurrence and poor cosmesis. A lack of ready access to radiotherapy centres (54.3\%) and delay/overcrowding of these facilities (42.5\%) were considered the major local challenges to BCS practice while delayed presentation and ignorance were implicated in $25.5 \%$ and $14.6 \%$ of the participants. 
The equivalence of BCS to TM was affirmed by $44.3 \%$ of the nurses; while $41.6 \%$ did not and $8.7 \%$ were unsure. $35.6 \%$ of the nurses had participated in the management of patients who had BCS while 3 in 5 nurses had not. $65.3 \%$ of the participants believed there is a paucity of information to make an informed decision for BCS. The major determinants for choosing between BCS and TM were believed to be personal opinion and preference (82.6\%), income and finance (70.8\%), surgical expertise (69.8\%), level of education (64.4\%), previous experiences $(63.9 \%)$, social status $(58.9 \%)$, age (58.9\%) and traditional belief (50.7\%).

BC: Breast Cancer; NR: No Response; ExB: Excision Biopsy; L: Lumpectomy; WLE: Wide Local Excision, Quad: Quadrantectomy; SM: Segmental Mastectomy; PM: Partial Mastectomy; Os: Others; ASD: Axillary sampling/ dissection; RT: Radiotherapy; Chemo: Chemotherapy; HT: Hormonal therapy; IT: Immune therapy; TM: Total Mastectomy; PNB: Preserve native breast; PNAB: Preservation of a woman's nude appearance and beauty; IPWQL: Improved psychological wellbeing and quality of life; LRR: Local Recurrence Risk; POP: Personal Opinion and Preference; TNE: Traditional Belief and Ethnicity RB: Religious Believe; LE: Level of Education; PE: Previous Experience; GL: Geographical Location; SE: Surgical Expertise; SS: Social Status; IF: Income/Finance

\section{ACCEPTABILITY OF BCS AND ASSOCIATION WITH ITS AWARENESS}

More than half of the participants (57.1\%) will accept BCS or recommend it to eligible friends or relatives as shown in Figure 2. Table 4 shows no statistical association between those who accepted BCS as a treatment option and their awareness (as defined) or duration of nursing practice. However, a significant correlation was observed between acceptance of BCS as a treatment option and awareness of its oncologic equivalence to TM. The knowledge and awareness of its oncologic equivalence to TM increased its acceptance among the nurses. Improved psychological satisfaction and QOL is top of the reasons for acceptance of BCS while recurrence is top of the reasons for nonacceptance. (Table 5) 
Table 3: Perception (Awareness and Knowledge) of BCS versus Mastectomy

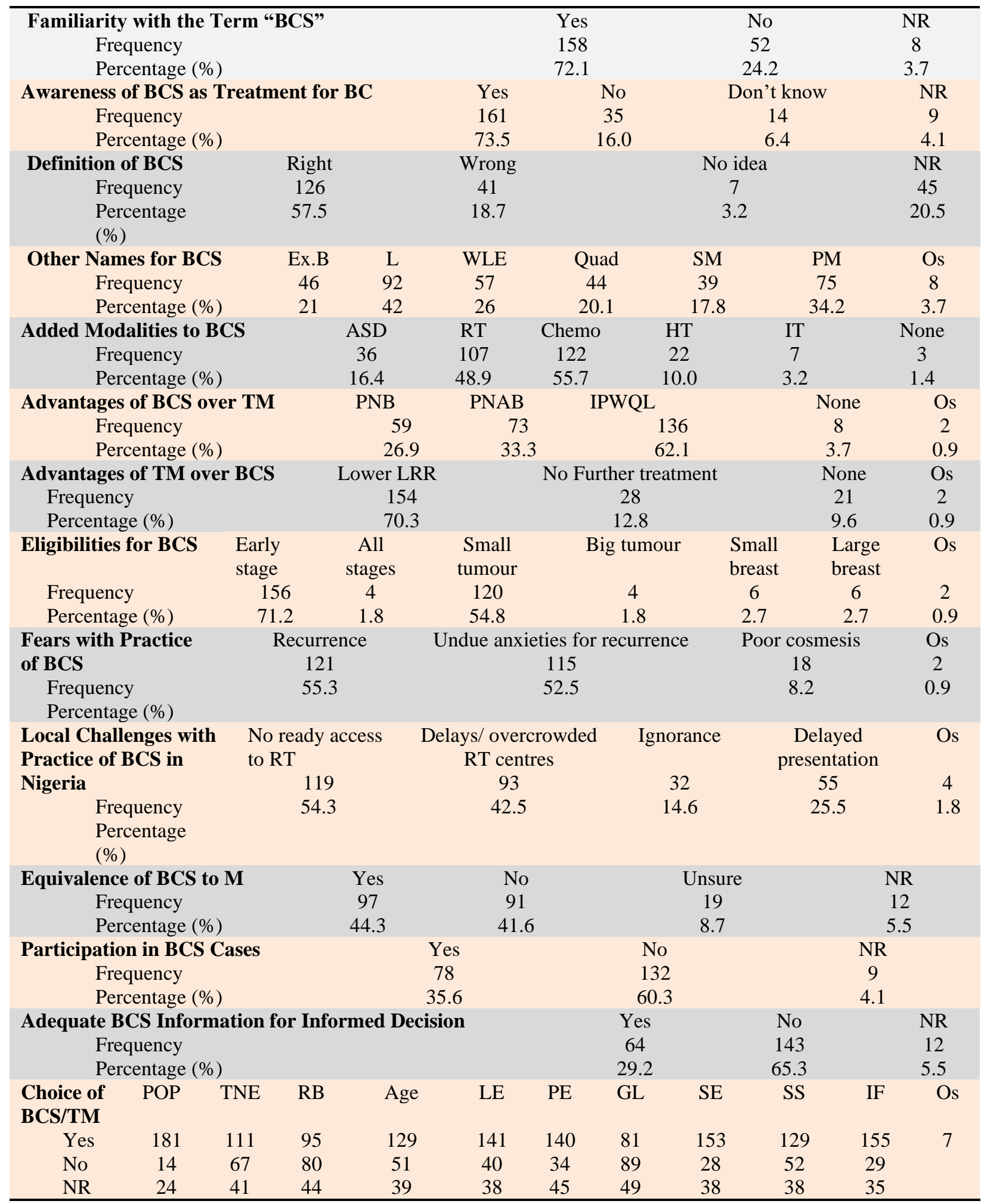




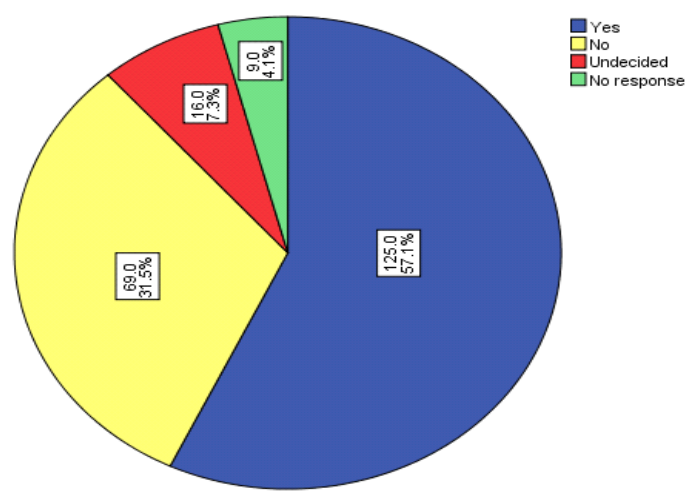

Figure 2: Acceptance of Breast Conservative Surgery

Table 4: Acceptance of BCS versus its Awareness, Years of Practice and Equivalence to TM

\begin{tabular}{|c|c|c|c|c|c|}
\hline & \multicolumn{4}{|c|}{ Acceptance of BCS } & \multirow{3}{*}{$\begin{array}{l}\mathrm{X}^{2} \\
\text { P-value } \\
\text { Inference }\end{array}$} \\
\hline & Yes & No & Undecided/ & Total & \\
\hline & & & No response & & \\
\hline \multicolumn{6}{|l|}{ Awareness of BCS } \\
\hline Aware & 79 & 34 & 13 & 126 & 3.882 \\
\hline Not Aware & 46 & 35 & 12 & 93 & 0.114 \\
\hline Total & 125 & 69 & 25 & 219 & Not significant \\
\hline \multicolumn{6}{|l|}{ Years of Practice } \\
\hline $1-3$ & 21 & 10 & 1 & 32 & 6.531 \\
\hline $4-6$ & 27 & 14 & 3 & 44 & 0.366 \\
\hline $7-9$ & 19 & 9 & 7 & 35 & Not significant \\
\hline 10 above & 58 & 36 & 14 & 108 & \\
\hline Total & 125 & 69 & 25 & 219 & \\
\hline \multicolumn{6}{|l|}{ Equivalence to TM } \\
\hline Yes & 66 & 23 & 8 & 97 & 22.733 \\
\hline No & 49 & 35 & 7 & 91 & 0.000 \\
\hline Unaware/no response & 10 & 11 & 10 & 31 & Significant \\
\hline Total & 125 & 69 & 25 & 219 & \\
\hline
\end{tabular}


Table 5: Reason for Acceptance and Non-acceptance of BCS as Treatment Option

\begin{tabular}{lll}
\hline \multicolumn{1}{c}{ Acceptance } & Frequency & Percent \\
\hline Preserve/conserve breast & 19 & 8.7 \\
Beauty/cosmesis/nude appearance & 21 & 9.6 \\
Improve psychology/satisfaction/quality of life & 23 & 10.5 \\
Safe oncologic equivalence to mastectomy & 11 & 5.0 \\
No specific reason & 44 & 20.1 \\
Non-applicable & 94 & 42.9 \\
Others & 7 & 3.2 \\
& & \\
Recurrence Non-acceptance & 43 & 19.6 \\
Uncertainty of its oncologic safety & 8 & 3.7 \\
Undue anxiety & 4 & 1.8 \\
No specific reason & 12 & 5.5 \\
Non-applicable & 149 & 68.0 \\
Others & 3 & 1.4 \\
\hline
\end{tabular}

\section{DISCUSSIONS}

BCS was endorsed by the National Institutes of Health Consensus Conference in 1990 and has since then become the standard of excellence in breast cancer management (NIH Consensus Conference, 1991). In the US, accredited breast centres are measured using the rate of performance of BCS for early breast cancers (National Accreditation Program for Breast Centres, 2013; Kummerow et al., 2015). The practice of BCS in Nigeria is low and is beset by various challenges peculiar to resource-limited settings including inadequate and inappropriate knowledge/awareness, limitations posed by eligibility criteria and radiotherapy requirements, low demands, limitations of oncoplastic surgery and breast reconstruction (Olasehinde et al., 2019).

This study explored the knowledge of BCS among 219 nurses in a rural teaching hospital in the southwest of Nigeria and their willingness to accept or recommend it as a safe oncological treatment for early-stage breast cancer. Participants consisted of nurses mostly 45 years and below corresponding to the age where the concept of breast preservation is expectedly an interesting consideration. Nearly a half (49.3\%) of the nurses have been practising for a duration not less than 10 years - a period reasonable to allow each nurse to participate in the management of a breast cancer woman with breast conservation modalities.

Despite claims of more than two-thirds of the participants to have heard the term "BCS" and were aware of its use as an alternative to mastectomy, only $57.5 \%$ of nurses could define or describe the concept in proper perspective. This was the category of nurses considered to be aware of BCS in the context of this discussion. Other terms used to describe BCS were lumpectomy, wide local excision, quadrantectomy, segmental resection, partial mastectomy and tylectomy (Dorval et al., 1998). In this study, lumpectomy and partial mastectomy were the most recognised terminologies for BCS. To prevent a recurrence of breast cancer, BCS is complemented by other treatment modalities such as axillary surgeries (sentinel lymph node biopsy, axillary sampling or dissection), radiotherapy, chemotherapy, hormonal therapy and target or immune therapy (Arriagada et al., 1996; van Dongen et al., 2000; Mahmood et al., 2012). $48.9 \%$ of participants in the study recognised the role of radiotherapy while only $16.4 \%$ acknowledged axillary surgery as an important component of breast conserving therapy. Fewer numbers recognised the role of hormonal and immune therapy. These knowledge gaps in the definition/description of BCS and its 
complementary treatment modalities may in part be due to inadequate clinical exposure of the nurses, deficient classroom education, failure of continued medical education and in-practice training/updates, low hospital BCS practice rate or a lack of engagement of nurses in clinical decision making in the hospital.

Osime et al. (2008) in a KAP study on breast cancer among 385 female civil servants in Benin city, among whom $72 \%$ were educated up to the tertiary level, found that only $49(12.7 \%)$ have heard of BCS. A poor perception of BCS was similarly demonstrated among Chinese breast cancer patients (CBCP) in a study in West China by Zhang Li et al. (2019) The study showed that only $2.42 \%$ of 1,324 patients had a greater perception of BCS, $12.69 \%$ had never heard of BCS, and $51.06 \%$ had only heard of BCS but did not have specific knowledge. There was no known similar research performed in nurses to compare the findings of this study. A feminine approach to counselling by informed female nurses is vital to assist patients to make the right decision. Without a proper understanding and a clear conviction by the nurses, the counselling of patients with early breast cancer for BCS will be an uphill task.

The advantages of BCS such as - improved psychological well-being and quality of life (QOL), preservation of nude appearance/beauty and preservation of native breast; were respectively recognised by $62.1 \%, 33.3 \%$ and $26.9 \%$ of the nurses in this study. Earlier studies observed a significant difference in mastectomized and breast conserved women in their perception of body image/configuration, nude appearance and sexual function with the spouse, leisure time activities especially activities that necessitate exposure of the body (eg athletics or swimming) and social isolation. However, the long-term frequency of mental/psychic dysfunction was not remedied by breast preservation (Meyer and Aspegren, 1989; Howes et al., 2016). Fear of recurrence (55.3\%) and undue anxieties over recurrence $(52.5 \%)$ were the major concerns given by participants about the practice of BCS in this study. In a Singaporean study, an exploration of the reasons given by women who were eligible for BCS but choose to undergo mastectomy revealed that the fear of recurrence was a major deterrent in $74 \%$ of the cases. Conceptually, many believed that TM (which is more radical than BCS) should offer patients a better guarantee to achieve a cure, a greater sense of security from recurrence and provide greater opportunity to avoid chemotherapy (Teh et al., 2014; Gu et al., 2017). This may explain why $70.3 \%$ believed TM lowers local recurrence rate compared to BCS in this study and $12.8 \%$ even considered there may be no need for further treatment after a TM. In reality, the survival and recurrence rates are equivalent in BCS and TM (Arriagada et al., 1996; van Dongen et al., 2000; Mahmood et al., 2012).

The major eligibility criteria for BCS in this study were early-stage breast cancer and small tumour size. Improvement in oncoplastic surgical techniques and good response to neoadjuvant chemotherapy has made feasible many cases that formerly were traditionally excluded from breast conservation. Currently, the contraindications to BCS are the patient's refusal and lack of motivation, unattainable free surgical margins, increase likelihood of poor cosmesis after BCS, known genetic susceptibility and instances when radiotherapy is contraindicated or not feasible (Morrow, 2005; Fajdic et al., 2013). Out of several limitations to BCS practices in Nigeria, radiotherapy challenges including a lack of access (54.3\%) and overcrowding of radiotherapy facilities (42.5\%) were top on the list followed by late presentation (25.5\%) and ignorance (14.6\%). Radiotherapy services, a critical component in breast-conserving therapy, are not readily available to a large number of patients in Nigeria - the most populated nation in Africa (Bajaj et al., 2004; Nwankwo et al., 2013). According to the International Atomic Energy Agency, Nigeria has the biggest gap between radiotherapy availability and its demand (Abdel-Wahab et al., 2013). Few radiotherapy centres in Nigeria 
leads to long travel distance for patients in rural locations, overcrowding of these centres and repeated damages to the machines.

This study observed that $57.1 \%$ of participants agree to accept BCS as a treatment option and this was statistically unrelated to the awareness of BCS in general. The finding buttresses an observation in several studies of the complexities involved in the decision-making process between BCS and TM (Teh et al., 2014; Bellavance and Kesmodel, 2016). The common determining factors are the patients' education status, personal beliefs, personal preferences, concerns about body image, sexuality and recurrence, partner's opinion and surgeon's recommendation (Teh et al., 2014). Shared decision-making that will accommodate the patients' concerns and autonomy with the expert medical opinion, is considered as the ideal (Bellavance and Kesmodel, 2016). The finding of a significant acceptance among those aware of their oncologic equivalence in this study suggests that a low BCS acceptance rate could result from a lack of awareness of an equivalent treatment option amongst patients, their providers and family members. This is supported by studies demonstrating a higher BCS acceptance among the younger and more literate women (Agrawal et al., 2012). With adequate knowledge, the likelihood of choosing BCS by an eligible patient is expected to rise. Patient pamphlets, interactive educational classes, interactive websites, audio booklets and media apps are useful decision aids that can enhance the shared decision-making process (Nicholas et al., 2016; Si et al., 2020).

\section{CONCLUSION}

This study demonstrated gaps in the knowledge of BCS among nurses who are stakeholders in assisting patients make the right decision. This knowledge gap in the perception of BCS will interfere with the ability of a nurse to adequately counsel patients in need of their expert opinion. Though there was no significant association between its awareness and acceptance in generality, a significantly higher level of acceptance of BCS was noted among those aware of its oncologic equivalence to TM. Drawing from these findings, an increase in public awareness and education of nurses on breast conservation for early breast cancer is required to improve the acceptance rate of BCS in our practice. Caregivers should also devise effective means of communication to encourage eligible patients for breast conservation.

\section{CONFLICTS OF INTEREST}

The authors declare that there are conflicts of interest in the participation and undertaking of this research

\section{ACKNOWLEDGEMENT}

The authors acknowledge the institution (Irrua Specialist Teaching Hospital) where this research was carried out and the nurses who participated in the study. 


\section{REFERENCES}

Abdel-Wahab, M., Bourque, J. M., Pynda, Y., Iżewska, J., Van der Merwe, D., Zubizarreta, E., \& Rosenblatt, E. (2013). Status of radiotherapy resources in Africa: an International Atomic Energy Agency analysis. The Lancet. Oncology, 14(4), e168-e175. https://doi.org/10.1016/S1470-2045(12)70532-6

Adebamowo, C. A., \& Adekunle, O. O. (1999). Case-controlled study of the epidemiological risk factors for breast cancer in Nigeria. The British journal of surgery, 86(5), 665-668. https://doi.org/10.1046/j.13652168.1999.01117.x

Adesunkanmi, A. R., Lawal, O. O., Adelusola, K. A., \& Durosimi, M. A. (2006). The severity, outcome and challenges of breast cancer in Nigeria. Breast (Edinburgh, Scotland), 15(3), 399-409. https://doi.org/10.1016/j.breast.2005.06.008

Agrawal, S., Goel, A. K., \& Lal, P. (2012). Participation in decision making regarding type of surgery and treatmentrelated satisfaction in North Indian women with early breast cancer. Journal of cancer research and therapeutics, 8(2), 222-225. https://doi.org/10.4103/0973-1482.98974

Ajekigbe A. T. (1991). Fear of mastectomy: the most common factor responsible for late presentation of carcinoma of the breast in Nigeria. Clinical oncology (Royal College of Radiologists (Great Britain), 3(2), 78-80. https://doi.org/10.1016/s0936-6555(05)81167-7

Akram, M., Iqbal, M., Daniyal, M., \& Khan, A. U. (2017). Awareness and current knowledge of breast cancer. Biological research, 50(1), 33. https://doi.org/10.1186/s40659-017-0140-9

Arriagada, R., Lê, M. G., Rochard, F., \& Contesso, G. (1996). Conservative treatment versus mastectomy in early breast cancer: patterns of failure with 15 years of follow-up data. Institut Gustave-Roussy Breast Cancer Group. Journal of clinical oncology : official journal of the American Society of Clinical Oncology, 14(5), 1558-1564. https://doi.org/10.1200/JCO.1996.14.5.1558

Bajaj, A. K., Kon, P. S., Oberg, K. C., \& Miles, D. A. (2004). Aesthetic outcomes in patients undergoing breast conservation therapy for the treatment of localized breast cancer. Plastic and reconstructive surgery, 114(6), 1442-1449. https://doi.org/10.1097/01.prs.0000138813.64478.a7

Bellavance, E. C., \& Kesmodel, S. B. (2016). Decision-Making in the Surgical Treatment of Breast Cancer: Factors Influencing Women's Choices for Mastectomy and Breast Conserving Surgery. Frontiers in oncology, 6, 74. https://doi.org/10.3389/fonc.2016.00074

Biganzoli, L., Wildiers, H., Oakman, C., Marotti, L., Loibl, S., Kunkler, I., Reed, M., Ciatto, S., Voogd, A. C., Brain, E., Cutuli, B., Terret, C., Gosney, M., Aapro, M., \& Audisio, R. (2012). Management of elderly patients with breast cancer: updated recommendations of the International Society of Geriatric Oncology (SIOG) and European Society of Breast Cancer Specialists (EUSOMA). The Lancet. Oncology, 13(4), e148-e160. https://doi.org/10.1016/S1470-2045(11)70383-7

Chen, A. M., Meric-Bernstam, F., Hunt, K. K., Thames, H. D., Oswald, M. J., Outlaw, E. D., Strom, E. A., McNeese, M. D., Kuerer, H. M., Ross, M. I., Singletary, S. E., Ames, F. C., Feig, B. W., Sahin, A. A., Perkins, G. H., Schechter, N. R., Hortobagyi, G. N., \& Buchholz, T. A. (2004). Breast conservation after neoadjuvant 
chemotherapy: the MD Anderson cancer center experience. Journal of clinical oncology : official journal of the American Society of Clinical Oncology, 22(12), 2303-2312. https://doi.org/10.1200/JCO.2004.09.062

Coleman, M. P., Quaresma, M., Berrino, F., Lutz, J. M., De Angelis, R., Capocaccia, R., Baili, P., Rachet, B., Gatta, G., Hakulinen, T., Micheli, A., Sant, M., Weir, H. K., Elwood, J. M., Tsukuma, H., Koifman, S., E Silva, G. A., Francisci, S., Santaquilani, M., Verdecchia, A., ... CONCORD Working Group (2008). Cancer survival in five continents: a worldwide population-based study (CONCORD). The Lancet. Oncology, 9(8), 730-756. https://doi.org/10.1016/S1470-2045(08)70179-7

Dorval, M., Maunsell, E., Deschênes, L., \& Brisson, J. (1998). Type of mastectomy and quality of life for long term breast carcinoma survivors. Cancer, 83(10), 2130-2138. https://doi.org/10.1002/(sici)1097$\underline{0142(19981115) 83: 10<2130:: \text { aid-cncr11>3.0.co;2-8 }}$

Dragun, A. E., Huang, B., Tucker, T. C., \& Spanos, W. J. (2012). Increasing mastectomy rates among all age groups for early stage breast cancer: a 10-year study of surgical choice. The breast journal, 18(4), 318-325. https://doi.org/10.1111/j.1524-4741.2012.01245.x

Elenwo, S.N. \& Ijah, R.F. (2020). Acceptance of Mastectomy among Patients Diagnosed with Breast Cancer in a Tertiary Hospital in Nigeria. Tropical Medicine \& Surgery, 8:228. https://doi.org/10.35248/23299088.8.2.228

Fajdic, J., Djurovic, D., Gotovac, N., \& Hrgovic, Z. (2013). Criteria and procedures for breast conserving surgery. Acta informatica medica: Journal of the Society for Medical Informatics of Bosnia \& Herzegovina: casopis Drustva za medicinsku informatiku BiH, 21(1), 16-19. https://doi.org/10.5455/AIM.2013.21.16-19

Fisher B. (1998). Lumpectomy (segmental mastectomy and axillary dissection). In: Bland KI, Copeland EMI, (Eds), The Breast: Comprehensive Management of Benign and Malignant Diseases $\left(1^{\text {st }} \mathrm{ed}, \mathrm{pp} .917\right)$. Philadelphia: WB Saunders.

Fisher, B., Anderson, S., Bryant, J., Margolese, R. G., Deutsch, M., Fisher, E. R., Jeong, J. H., \& Wolmark, N. (2002). Twenty-year follow-up of a randomized trial comparing total mastectomy, lumpectomy, and lumpectomy plus irradiation for the treatment of invasive breast cancer. The New England journal of medicine, 347(16), 1233-1241. https://doi.org/10.1056/NEJMoa022152

Gu, J., Groot, G., Holtslander, L., \& Engler-Stringer, R. (2017). Understanding Women's Choice of Mastectomy Versus Breast Conserving Therapy in Early-Stage Breast Cancer. Clinical Medicine Insights. Oncology, 11, 1179554917691266. https://doi.org/10.1177/1179554917691266

Howes, B. H., Watson, D. I., Xu, C., Fosh, B., Canepa, M., \& Dean, N. R. (2016). Quality of life following total mastectomy with and without reconstruction versus breast-conserving surgery for breast cancer: A casecontrolled cohort study. Journal of plastic, reconstructive \& aesthetic surgery: JPRAS, 69(9), 1184-1191. https://doi.org/10.1016/j.bjps.2016.06.004

Jedy-Agba, E., Curado, M. P., Ogunbiyi, O., Oga, E., Fabowale, T., Igbinoba, F., Osubor, G., Otu, T., Kumai, H., Koechlin, A., Osinubi, P., Dakum, P., Blattner, W., \& Adebamowo, C. A. (2012). Cancer incidence in Nigeria: a report from population-based cancer registries. Cancer Epidemiology, 36(5), e271-e278. https://doi.org/10.1016/j.canep.2012.04.007 
Kummerow, K. L., Du, L., Penson, D. F., Shyr, Y., \& Hooks, M. A. (2015). Nationwide trends in mastectomy for early-stage breast cancer. JAMA Surgery, 150(1), 9-16. https://doi.org/10.1001/jamasurg.2014.2895

Lee, W. Q., Tan, V., Choo, H., Ong, J., Krishnapriya, R., Khong, S., Tan, M., Sim, Y. R., Tan, B. K., Madhukumar, P., Yong, W. S., \& Ong, K. W. (2018). Factors influencing patient decision-making between simple mastectomy and surgical alternatives. BJS Open, 3(1), 31-37. https://doi.org/10.1002/bjs5.50105

Mac Bride, M. B., Neal, L., Dilaveri, C. A., Sandhu, N. P., Hieken, T. J., Ghosh, K., \& Wahner-Roedler, D. L. (2013). Factors associated with surgical decision making in women with early-stage breast cancer: a literature review. Journal of women's health, 22(3), 236-242. https://doi.org/10.1089/jwh.2012.3969

Mahmood, U., Morris, C., Neuner, G., Koshy, M., Kesmodel, S., Buras, R., Chumsri, S., Bao, T., Tkaczuk, K., \& Feigenberg, S. (2012). Similar survival with breast conservation therapy or mastectomy in the management of young women with early-stage breast cancer. International journal of radiation oncology, biology, physics, 83(5), 1387-1393. https://doi.org/10.1016/j.ijrobp.2011.10.075

Meyer, L., \& Aspegren, K. (1989). Long-term psychological sequelae of mastectomy and breast conserving treatment for breast cancer. Acta oncologica (Stockholm, Sweden), $28(1), \quad 13-18$. https://doi.org/10.3109/02841868909111174

Mieog, J. S., van der Hage, J. A., \& van de Velde, C. J. (2007). Neoadjuvant chemotherapy for operable breast cancer. The British journal of surgery, 94(10), 1189-1200. https://doi.org/10.1002/bjs.5894

Morrow M. (2005). Limiting breast surgery to the proper minimum. Breast (Edinburgh, Scotland), 14(6), 523-526. https://doi.org/10.1016/j.breast.2005.08.008

Morrow, M., Strom, E. A., Bassett, L. W., Dershaw, D. D., Fowble, B., Giuliano, A., Harris, J. R., O'Malley, F., Schnitt, S. J., Singletary, S. E., Winchester, D. P., American College of Radiology, American College of Surgeons, Society of Surgical Oncology, \& College of American Pathology (2002). Standard for breast conservation therapy in the management of invasive breast carcinoma. CA: a cancer journal for clinicians, 52(5), 277-300. https://doi.org/10.3322/canjclin.52.5.277

National Accreditation Program for Breast Centres. (2013). Breast Cancer Standards Manual. Chicago, IL: American College of Surgeons.

Nicholas Zdenkowski, Butow, P., Tesson, S., \& Boyle, F. (2016). A systematic review of decision aids for patients making a decision about treatment for early breast cancer. Breast (Edinburgh, Scotland), 26, 31-45. https://doi.org/10.1016/j.breast.2015.12.007

NIH consensus conference. Treatment of early-stage breast cancer. (1991). JAMA, 265(3), 391-395.

Nwankwo, K.C., Dawotola, D.A., Sharma, V. (2013). Radiotherapy in Nigeria: Current status and future challenges. West African Journal of Radiology, 20(2), 84-88. [cited 2021 Sep 18]. Available from: https://www.wajradiology.org/text.asp?2013/20/2/84/121099

Ogundiran, T. O., Ayandipo, O. O., Ademola, A. F., \& Adebamowo, C. A. (2013). Mastectomy for management of breast cancer in Ibadan, Nigeria. BMC surgery, 13, 59. https://doi.org/10.1186/1471-2482-13-59

Olasehinde, O., Arije, O., Wuraola, F. O., Samson, M., Olajide, O., Alabi, T., Arowolo, O., Boutin-Foster, C., Alatise, O. I., \& Kingham, T. P. (2019). Life Without a Breast: Exploring the Experiences of Young Nigerian Women 
After Mastectomy for Breast Cancer. Journal of global oncology, 5, 1-6. https://doi.org/10.1200/JGO.18.00248

Osime OC, Okojie O, Aigbekaen ET, Aigbekaen IJ. (2008). Knowledge attitude and practice about breast cancer among civil servants in Benin City, Nigeria. Ann Afr Med, 7(4), 192-197. https://doi.org/10.4103/1596$\underline{3519.55654}$

Si, J., Guo, R., Lu, X., Han, C., Xue, L., Xing, D., \& Chen, C. (2020). Decision aids on breast conserving surgery for early stage breast cancer patients: a systematic review. BMC medical informatics and decision making, 20(1), 275. https://doi.org/10.1186/s12911-020-01295-8

Singletary S. E. (2002). Surgical margins in patients with early-stage breast cancer treated with breast conservation therapy. American journal of surgery, 184(5), 383-393. https://doi.org/10.1016/s0002-9610(02)01012-7

Teh, Y. C., Shaari, N. E., Taib, N. A., Ng, C. H., See, M. H., Tan, G. H., Jamaris, S., \& Yip, C. H. (2014). Determinants of choice of surgery in Asian patients with early breast cancer in a middle income country. Asian Pacific journal of cancer prevention: APJCP, 15(7), 3163-3167. https://doi.org/10.7314/apjcp.2014.15.7.3163

Thompson, C., Cullum, N., McCaughan, D., Sheldon, T., \& Raynor, P. (2004). Nurses, information use, and clinical decision making - the real world potential for evidence-based decisions in nursing. Evidence-based nursing, 7(3), 68-72. https://doi.org/10.1136/ebn.7.3.68

van Dongen, J. A., Voogd, A. C., Fentiman, I. S., Legrand, C., Sylvester, R. J., Tong, D., van der Schueren, E., Helle, P. A., van Zijl, K., \& Bartelink, H. (2000). Long-term results of a randomized trial comparing breastconserving therapy with mastectomy: European Organization for Research and Treatment of Cancer 10801 trial. Journal of the National Cancer Institute, 92(14), 1143-1150. https://doi.org/10.1093/jnci/92.14.1143

Zhang I, Gao J, Lin D, Xie I, Wang T, Zou L. (2019). Personal factors influencing breast cancer patients' perception of breast conservation surgery in West China. Ann Transl Med, 7(14), 313. https://doi.org/10.21037/atm.2019.06.43 